Brit. J. vener. Dis. (1957), 33, 112.

\title{
INFECTION AND RE-INFECTION IN EARLY SYPHILIS*
}

\author{
BY \\ E. E. PREBBLE \\ Director, Special Clinics, Liverpool Royal Infirmary and Seaman's Dispensary, Liverpool
}

In these days, when modern treatment and enlightened propaganda have reduced the incidence of early syphilis in Great Britain to a small percentage of the pre-war figure, the following account seems worthy of notice.

\section{Case Report}

On May 30, 1956, a male patient aged 28 years reported at the Special Diseases Clinic of the Liverpool Royal Infirmary and complained of sores on the penis, which, he stated, had been present for 2 weeks. He gave a history of extra-marital intercourse 3 weeks and 5 weeks previously with different consorts, and of marital intercourse shortly before his sores appeared.

On examination, he was found to have two small herpetic-like lesions on the dorsal aspect of the glans penis and one indurated lesion on the dorsal aspect of the prepuce which was oozing serum. There were palpable left inguinal glands but no other clinical signs of syphilis. Dark-ground examination revealed large numbers of Treponema pallidum and the Wassermann reaction (WR) and Kahn test were negative. A diagnosis of sero-negative primary syphilis was made, and, from May 30 to June 11 inclusive, he received ten daily injections each of 600,000 units penicillin (PAM). On completion of the treatment, the sore was healed.

Meanwhile, in spite of repeated requests, the wife failed to present herself for examination and did not finally report to the clinic until July 13, 2 months after the first attendance of the husband and 6 weeks after he had completed treatment. She complained of a lump "down below" and dyspareunia 5 days before. On examination, she had bilateral inguinal adenopathy and a circular ulcer about $\$$ inch in diameter, secondarily infected, on the internal surface of the left labium minus. A dark-ground examination revealed many active treponemata and her WR and Meinicke and Kahn tests were all positive. From July 13 to 27 , she received ten daily injections, each of 600,000 units penicillin (PAM) and on completion of treatment the lesion had healed.

\footnotetext{
* Received for publication April 25, 1957.
}

On August 15, the husband again reported to the ctinic, when he was found to have small multiple herpetic lesions on the prepuce. Dark-ground tests were repeatedly negative for $T$. pallidum and the WR and Kahn test were also negative. The next time that he reported was on November 19, when he complained of a sore on the prepuce. On examination, a typical primary ulcer was again present and dark-ground examination revealed large numbers of $T$. pallidum. The WR and Kahn and Meinicke tests were all positive. He was given a further course of ten daily injections 600,000 units penicillin (PAM) from November 19 to 30 . He has not reported since that date.

Meanwhile, the wife reported on November 13, almost 4 months after her treatment was completed. She had no signs of disease and her WR and Kahn test were negative. On November 20, she again reported complaining of soreness and discomfort and was found to have a typical primary lesion on the inner surface of the left labium minus with inguinal adenopathy. Dark-ground tests were positive for $T$. pallidum and daily penicillin treatment was given for 10 days, being completed on November 30. After three injections had been given, the blood was examined and the WR found doubtful $1 / 2$, the Meinicke doubtful and the Kahn positive one plus.

She was next seen on January 10 when she had no clinical signs and her WR and Kahn test were negative.

\section{Comment}

So-called "ping-pong" infection with gonorrhoea is comparatively common, but must be much more unusual in the case of syphilis. The above report illustrates, I believe, the effectiveness of penicillin treatment of early syphilis, and at the same time stresses the necessity for the examination of contacts during the incubation period of the disease. It should be unnecessary to add that the patients should be kept under clinical and serological examination for a period of not less than 2 years after completion of treatment. 